\title{
Chandigarh Kare Aashiqui: Bollywood, bioethics, and trans bodies
}

\author{
ROHIN BHATT, KRIS CHUDAWALA
}

\section{Chandigarh Kare Aashiqui. Producers: Bhushan Kumar, Pragya Kapoor, Krishan Kumar, Abhishek Nayyar, Director: Abhishek Kapoor, Hindi, 120 minutes, 2021.}

\section{Introduction}

Art has become a central tool in bioethics discourses across the world and in challenging the ethics of discourse and extending our moral imagination about life and existence. In the last two decades, the Hindi film industry has seen a cavalcade of films that grapple with bioethical issues. From IVF in Good Newwz (2019) to geriatric pregnancy in Badhaai Ho (2018), from surrogacy in Chori Chori Chupke Chupke (2001) to sperm donation in Vicky Donor (2012), there seems to be a fascination with bioethics and medical processes as plot points for Bollywood films. These films provide powerful narratives which can potentially play a role in destigmatising some of these issues, improving public literacy, and initiating debates on hitherto taboo topics. However, the subject matter is often not treated with the required sensitivity or is written with elements of horror and/or comedy, with disastrous effects. Chandigarh Kare Aashiqui has missed the mark by a mile in its representation of a transgender character, in a movie that sought to normalise queer relationships. Bollywood's treatment of a queer subject made for a cisgender heteronormative audience must be careful and sensitive to the ground realities of the queer community or it risks promoting transphobia and

Authors: Rohin Bhatt, (corresponding author rohinbhatt1998@gmail.com), Master of Bioethics Student, Harvard Medical School, Harvard, Boston MA 02215 USA; Kris Chudawala (sortakris@gmail.com), Artist and Trans Rights Activist, Mumbai, INDIA.

To cite: Bhatt R, Chudawala K. Chandigarh Kare Aashiqui: Bollywood, bioethics, and trans bodies. Indian J Med Ethics. Published online first on February 5, 2022. DOI: 10.20529/IJME.2022.008

Manuscript Editor: Sanjay A Pai

Copyright and license

COndian Journal of Medical Ethics 2022: Open Access and Distributed under the Creative Commons license (CC BY-NC-ND 4.0), which permits only non-commercial and non-modified sharing in any medium, provided the original author(s) and source are credited. queerphobia, and the consequent disastrous cascading effects on trans/queer rights.

\section{Plot and themes}

Played by Ayushmann Khurrana, Manu Munjal is a hypermasculine bodybuilder who is desperate to win a cross-fit competition and save his gym from failing. Maanvi Brar, played by Vaani Kapoor, is introduced into the film as the new Zumba teacher for Manu's gym. In true Bollywood fashion, a love story blossoms. The central theme of this film is not sensitising the audience about gender. It instead focuses on how Manu Munjal, deals with (and eventually accepts) the fact that the woman he loves is a transgender person. The transness of the protagonist Maanvi Brar is a mere plot point in this film which is used to push forward the exploration of Manu's conservative cisgender world. The film sets up the first half as a typical romantic comedy until there is a twist. Maanvi has a secret to share, but Manu is too much in love to care. There is a moment of anagnorisis when Manu proposes marriage and Maanvi is forced to disclose her identity as a transgender woman and her past medical history of having undergone gender affirmation surgery. This serves as a turning point in the film. Manu who is shocked by this then continues to misgender Maanvi and spews a litany of transphobic and violent threats towards her. The rest of the film covers Manu's journey of learning better and accepting Maanvi, while she continues to deal with transphobia not only from her mother but also from Manu's friends and family.

From a bioethical perspective, there is a need to analyse how the protagonist Maanvi Brar, a transgender character, played by a cisgender actress, Vaani Kapoor is continuously medicalised throughout the film. For the sake of clarity, cisgender refers to a person whose sense of gender identity matches with their biological sex. The film draws a dichotomy between her, a cis passing trans woman and a trans woman who does not have passing privilege. For the sake of clarity, we will define the terms: cis-passing refers to a transgender person who can pass as a cisgender person of the gender they identify with. Passing is based on how a person appears visually and how well they conform to the beauty standards of their gender identity. A trans person may have passing privilege with or without medical intervention. The film also includes graphic footage of penile inversion surgery, a form of gender affirmative surgery for 
trans women, takes medicalisation of its portrayal to an extreme, promoting bio-essentialism and is thus, a major point of concern for bioethicists. Bio-essentialism or biological essentialism is the idea that we are born with immutable traits by virtue of our sex. This also has implications in the larger scheme of transgender rights that are under threat in India with the Transgender (Protection of Rights) Act, 2019, which requires trans people to compulsorily subscribe to some sort of medical intervention before they are eligible to legally change their gender identity in government documents.

\section{The portrayal of the medicalisation of gender}

The central issue with Chandigarh Kare Aashiqui remains the medicalisation of the transgender identity. It associates medical intervention as the "right thing to do", suggesting that a transgender person must undergo gender-affirmative surgery, hormone replacement therapy (HRT) and many more cosmetic surgeries before they can be considered a "normal" person. The same is drilled into the audience by the consistent depiction of the medical processes the protagonist Maanvi Brar is said to have undergone. The first scene where she is introduced starts with her popping oestrogen tablets (HRT), and the montage that follows shows her at her regular appointment for facial hair laser removal. Whether such medical portrayal is even accurate for a 6-year post-op trans woman, is unclear. However, besides this, these scenes and Maanvi's speech about her transition make it clear, that only because she has medically transitioned, she is a normal person whom Manu and others should accept, as now she has made herself acceptable. As mentioned earlier, this is in resonance with how the Trans Act has structured conditions over access to care and justice for trans people and creates a narrative that portrays an idealised and acceptable version of transness. Any reality which does not then fall into this narrative is cast aside as being non-normative. Such a medicalised understanding of gender places on the marginalised communities, a burden of conformity in blatant disregard of poor outcomes, logistical barriers, or the pain and discomfort of medical procedures (1). The film conveniently downplays this and as some trans persons have already pointed out, this shows a clear lack of research on the part of the filmmakers (2).

The film also plays into the trope of otherisation of transgender people based on their conformity to cisgender society, and thus, ends up advocating that only trans people who have undergone gender-affirmative surgeries are valid, framing gender in a narrow, biologically essentialist frame. This is seen very evidently when the film draws a comparison between the protagonist Maanvi Brar, who is a cis passing, educated and rich trans woman, and the trans person on the street who engages in traditional forms of earning like mangti. Mangti refers to begging, in which trans persons from traditional groups like the Hijra community, clap and bless persons and beg for money on the streets. This film uses the character of the trans woman on the street to dictate to the audience what should be considered normal and respectable, and what can be shunned by society without any guilt. As
Ayushmann's character, Manu Munjal, looks to speak with this trans person, to try and understand what being transgender means, she goes on to explain that Maanvi is normal because she underwent surgery at the "right time". Furthermore, it is revealed that this trans person is educated, and yet engages in begging. The filmmakers presumably intend to convey the impact of transitioning and cis passing on a trans person. This sets a very negative precedent for the film's audience that only a cis passing trans person, is capable of contributing to society, thus, giving them a valid status and respectability. When this is placed in a broader framework, including the risk posed to transgender individuals by the Citizenship Amendment Act and the Trans Act, (CAA-NRC) the film might prove dangerous in laying down the norms of what transness is. The CAA-NRC will force trans persons to prove their lineage. Trans persons often face abuse and trauma through familial structures and are often forced to flee their houses. Trans persons also might not look the same as they do on their identity documents adding another layer of complexity to proving their identities. This will further dissuade them from transitioning. There needs to be heightened discourse on the CAA- NRC as a bioethical issue and how the medicalisation of gender will affect trans lives.

\section{Conclusion}

Movies and art do indeed play a role in furthering our moral imaginations and provide a starting point for debates in bioethics. Studies have shown that a positive representation in the media of transgender persons often changes the attitudes of people, even conservatives, for the better. They say that the road to hell is paved with good intentions. Chandigarh Kare Aashiqui is a prime example of that. While the movie might have made claims that they wish to normalise queer romance and spread awareness about transgender persons, it has instead played into stereotypes around trans persons in a badly researched and failed attempt to initiate any conversation. As Satvik put it, the movie was, 'transphobic content hiding under wokeism.' (2)

The film has taken the approach of presenting trans persons as "normal" to "spread awareness". Add to this the need for medicalisation, indicating that as long as a trans person is willing to spend lakhs of rupees to get the best surgical interventions possible, and appear to be cis passing, they are normal and the society should accept them as they can now blend into the mainstream of the society (whatever it may be). This is the film's intention as the film casts a cisgender actress Vaani Kapoor for the role of a trans person, who may have many beautiful features that most cisgender women can only aspire for, let alone any trans woman. In contrast, the film production had no qualms about hiring a transgender actor for the role of the trans person on the street, as this was intended to depict what was unacceptable. It is, therefore, safe to say that this film has centred its dictation of what is normal and acceptable, based on medical interventions, therefore failing at 
spreading any awareness, but has rather conveyed a very dangerous message to the audience watching. Medicalisation of queer bodies does little favour to queer people or the researchers working with them. An inaccurate portrayal of medicalised queer bodies paired with the widespread ignorance around trans rights will enable transphobia and continue to put queer and trans rights at risk.

\section{References}

1. Richie CS. Not Sick: Liberal, Trans, and Crip Feminist Critiques of Medicalization. J Bioethical Inq. 2019 Sep [cited 2021 Dec 18];16(3): 375-87. Available from: http://link.springer.com/10.1007/s11673019-09922-4

2. Satvik. "Phobia, Not Representation": Trans Person Reviews Chandigarh Kare Aashiqui. Quint. 2021 Dec 12 [cited 2021 Dec 18]; Available from: https://www.thequint.com/voices/blogs/transperson-reviews-chandigarh-kare-aashiqui\#read-more\%23readmore\#read-more 